\title{
Biochemical Assesment of Salivary Parameters in Young Patients with Dental Lesions
}

\author{
SORINA MIHAELA SOLOMON², MARILENA BATAIOSU2*, DORA MARIA POPESCU3*, ANNE MARIE RAUTEN²*, \\ DORIN NICOLAE GHEORGHE ${ }^{3}$, ROXANA ADINA PETRESCU², GEORGE ALEXANDRU MAFTEI ${ }^{4}$, CAMELIA FIERA MAGLAVICEANU ${ }^{2}$ \\ ${ }^{1}$ Grigore T. Popa University of Medicine and Pharmacy of lasi, Department of Periodontology, 16 Universitatii Str., 700115, Iasi, \\ Romania \\ 2University of Medicine and Pharmacy of Craiova, Department of Pedodontics, 2 Petru Rares Str., 200349, Craiova, Romania \\ 3University of Medicine and Pharmacy of Craiova, Department of Periodontology, 2 Petru Rares Str., 200349, Craiova, Romania \\ ${ }^{4}$ Grigore T. Popa University of Medicine and Pharmacy of lasi, 16 Universitatii Str., 700115, Iasi, Romania
}

\begin{abstract}
Dental injuries, especially those in the frontal area, through the complications they can cause, are an important topic due to the psychosocial impact they have on young patients. Saliva is an important biological resource, useful for conducting diagnostic tests; also, it can be harvested non-invasively, without the need for prior training or special equipment. The biochemical analysis of the concentration of salivary parameters may suggest the susceptibility and resistance to carious lesions. The aim of the present study is to evaluate a causal relationship between the values of salivary parameters, salivary calcium, phosphates and salivary $\mathrm{pH}$, and the incidence of dental caries.
\end{abstract}

Keywords: salivary biomarkers, dental lesions, salivary $\mathrm{pH}$

During childhood, dental injuries in the frontal area are an important subject both through the local complications that they can cause and by the psychosocial impact they have on the child and young adolescent.

Saliva contains calcium and phosphate in concentrations that make it supersaturated to all calcium phosphate salts. Calcium is a bivalent ion excreted together with salivary proteins in the lumen of the acinus. Therefore, the concentration of calcium in saliva depends on the salivary flow in the same way as in the case of proteins. The ionized calcium fraction is about $50 \%$ and it strongly depends on the salivary pH [1].

In the specialized literature we find a large number of publications regarding the concentrations of salivary parameters and their role in caries disease [2]. The composition of saliva is influenced by bivalent cations, such as $\mathrm{Ca}^{2}, \mathrm{Mg}^{2}, \mathrm{Zn}^{2}$ etc. [ 1,3$]$ Due to the presence of calcium and phosphate ions, saliva has a great potential for enamel remineralisation.

The mineral component of enamel, dentine and cement is hydroxyapatite. At a neutral $\mathrm{pH}$, hydroxyapatite is in balance with the oral medium, saturated with $\mathrm{Ca}^{2+}$ and $\mathrm{PO}_{n}{ }^{3}\{$ ions [4]. Demineralization is a reversible process if the $\mathrm{pH}$ is neutral and sufficient ions of $\mathrm{Ca}^{2} \mathrm{z}$ and $\mathrm{PO}_{4}{ }^{-3}$ are present in the oral liquid medium. Remineralisation consists of precipitating calcium and phosphate ions from the oral medium in the form of insoluble Ca phosphates which are incorporated into demineralized enamel [5].

Currently, saliva is an importantbiological resource useful for carrying outnew diagnostic tests. It has some important advantages from which we can specify that it can be harvested non-invasively from patients, without the need for prior training or special equipment [6].

\section{Experimental Part}

The present study proposes a way of evaluating both the susceptibility and the resistance to carious lesions, depending on the salivary parameters, having as main objective the evaluation of a causal relation between the values of these salivary parameters (salivary calcium, phosphates and salivary $\mathrm{pH}$ ) and the incidence of dental caries. The incidence of carious lesions in the studied patients was monitored by assessing oral health. We performed the research of the types of correlations with statistical significance between the studied salivary parameters and the analysis of the relationship between the salivary parameters and the dental status of the studied patients.

The study was performed on a study group formed by 67 children and adolescent patients, of both sexes, between the ages of 4 and 18 years old, in the Pedagogical Clinic of the Faculty of Dental Medicine Craiova, between years 2018-2019. Each patient participating in the study had a personal file, listing the personal data, familial and personal medical history, eating habits, the environment in which she spends the most time per day, the diagnosis and the treatment plan. Initially, we evaluated oral hygiene, then performed a professional mechanical brushing, used the water jet from the air-water syringe of the unit to wash the teeth abundantly and dried for 5 seconds with the air jet from the air-water syringe of the unit. The examination was performed by inspection and probing with the help of the mirror and rigid probe from the dental kit. If the existence of the dental lesion at the level of the front teeth was observed, we indicated the radiological examination by means of the technique of orthoradial and isometric radiography, bitewing radiographs or orthopantomographs. The obtained data were collected and statistically interpreted.

The saliva samples were collected under restconditions, during the consultation and then centrifuged, at a centrifugal force of $1,000 \mathrm{~g}$, for 10 minutes to remove bacteria and other residues. The resulting fluid was used for biochemical examinations. All biochemical determinations were performed using 912 HITACHI Roche Diagnostics and Diasys reagents. Total calcium analysis was performed with a photometric test using 
cresolphthalein complexone. The phosphate was quantified using phosphomolibdate/UV method. The salivary $\mathrm{pH}$ values were determined by the potentiometric method, an electrochemical method that is based on the measurement of the electric potential difference that is established between two electrodes introduced in the solution to be analysed.

\section{Results and discussions}

The results obtained from the study were in accordance with those of the studied literature. Thus, following the age groups of patients, we found that patients aged 4-6 years represented $40.29 \%$ of the study group (27 patients), those aged 7-11 - 23.88\% (16 patients), and those between 12 and 18 years old represented $35.82 \%$ of the subjects ( 24 patients).

Of the group of 67 patients, 44 were predominantly female, accounting for $65.67 \%$ of the total number of participants, while only 23 were male, representing $34.33 \%$ of the total number of participants.

Regarding the incidence of dental lesions, we observed that 26 patients (38.81\%) suffered dental-alveolar trauma in the frontal area, 23 subjects (34.33\%) had caries in the frontal area and 18 subjects had structural abnormalities (26.86\%).

Moreover, of the 23 patients with carious lesions in the frontal area, 10 patients ( $43.38 \%$ ) were female and 13 male (56.62\%). A similar distribution of trauma during childhood can be observed, out of the 26 cases $15(57.69 \%)$ are male and nine female (34.62\%). It is notew orthy that the severity of both dental caries and traumatic injury is increased in male patients.

Most of the registered cases were in the period of primary dentition - 10 patients, representing $43.48 \%$, and only seven cases in the secondary dentition, representing $30.43 \%$, the remaining five patients, representing $21.74 \%$, having mixed dentition.

We observed that in the primary dentition there were several multiple, symmetrical carious lesions in the entire frontal group, while the permanent teeth developed the most common single or mirror caries processes.

While of the 30 children who presented these lesions during secondary dentition, only eight benefited from systemic prophylactic fluoride therapy until the age of 12 , five patients benefited from local prophylactic fluoride therapy between 6 and 14 years old; the rest of the examined children (17) did not benefit from any prophylactic therapy.

Moreover, we could find that of the 13 patients who had dental dystrophies in the primary dentition, seven had the same pathology in the deciduous teeth, four had an increased caries risk and only two had no carious pathology in the final dentition until 18 years.

Considering that most of the time children arrive in a dental practice with severe dental caries, in 1996, the American Academy of Paediatric Dentistry (AAPD) took a position on oral and dental health of these patients, recommending that the first specialized control be performed within six months after the eruption of the first temporary tooth on the dental arches [7].

The results of our study supported the conclusion of Ru Shing Tang that children who had early caries were found to be at risk for anaemia and iron deficiency. SECC may be a contributing factor in iron deficiency, anaemia and weight loss in young children, but may also be a risk factor for anaemia in preschool children [8].

In the dental medicine of the last years, a series of modern techniques have been introduced which, besides the traditional ones, measure the tissue changes, thus helping to detect carious lesions before the cavity presence. These favour the establishment of an early prophylactic treatment, thus reducing the need for restorative work [9]. In addition, local and systemic changes associated with related dental treatments [10-12] or the presence of systemic modifying factors [13] should be considered, both in young and adult patients [14-16].

During the period of primary dentition, there may be difficulties of cooperation with the child in the case of a radiological examination. Therefore, its realization is not indicated when all proximal surfaces can be clinically visualized and examined through the phenomenon of diastema. This complementary examination is indicated to be performed periodically, especially for the detection of incipient caries on the proximal surfaces or those located at the point of contact that did not undermine the marginal ridge (especially bitewing radiographs) [17-19].

Following the analysis of the correlations between salivary parameters in female patients, we observed higher values of salivary calcium in those with few carious lesions. We also obtained high values of salivary $\mathrm{pH}$ and salivary phosphates in patients with few carious lesions, increases in salivary calcium, leading to increases in $\mathrm{pH}$. As Damle shows, calcium and phosphate levels are not statistically significant in patients who have carious lesions when compared to those who do not have such lesions [20].

Depending on age, the situation is similar, with the exception of the 7-11 age group, where it can be said that there is no statistical significance between the high values of salivary phosphates and $\mathrm{pH}$, nor between the values of salivary phosphates obtained in the patients with small number of carious lesions. Similar data have been presented in other studies [21, 22]. High values of salivary calcium were obtained at the same time with low values of salivary phosphates and small number of carious lesions and low values of salivary $\mathrm{pH}$ were obtained in patients with multiple carious lesions.

In the male patients there is a statistically significant difference between the values of the analysed salivary parameters and the number of carious lesions. Salivary phosphate and $\mathrm{pH}$ values are higher in patients with reduced number of carious lesions.

High values of salivary calcium were determined in patients with high $p H$ values and few carious lesions, and low values of salivary phosphates were obtained in those with multiple carious lesions. Also, salivary $\mathrm{pH}$ values in patients with numerous carious lesions were low, as we have found in other studies $[23,24]$.

An important factor in the prevention of carious lesions is the remineralisation of incipient forms, a phenomenon that requires the precipitation of calcium, phosphate and fluoride ions present in saliva $[25,26]$. Calcium and phosphate concentrations in saliva have a significant influence on the mechanisms of protection of the hard dental tissues in the oral cavity [27].

The evaluation of salivary parameters in the 7-11 age group shows that there are no statistically significant correlations between the values of the salivary parameters and the number of carious lesions. However, we observed the decrease of the number of carious lesions but also of the values of salivary phosphates, as well as the slight increase of the average values of the salivary calcium and the salivary $\mathrm{pH}$.

The evaluation of salivary parameters in the 12-18 years age group, in both sexes, does not show significant 
statistical correlations between the values of the salivary parameters and the number of carious lesions.

\section{Conclusions}

The values of the salivary parameters (calcium, phosphates and $\mathrm{pH}$ ) were statistically significantly higher in the patients with a small number of dental lesions, compared with the patients who had multiple carious lesions.

In both female and male patients, statistically significant differences are maintained for each salivary parameter between patients with multiple carious lesions and those with few carious lesions.

However, we observed the decrease of the number of dental lesions and also the slight increase of the average values of salivary calcium, phosphates and salivary $\mathrm{pH}$.

\section{References}

1.KAUR, A., KWATRA, K.S., KAMBOJ, P., J. Indian. Soc. Pedod. Prev. Dent., 30, no.3, 2012, p. 212.

2.MURARIU, A., FORNA AGOP, D., MANOLACHE, F., et al., Rom. J. Oral Rehab., 9, no. 3, 2017, p. 48.

3.NICOLAE, V., NEAMTU, B., PICU, O., MARTU-STEFANACHE, M.A., IBRIC- CIORANU, V.S., Rev. Chim. (Bucharest), 67, no. 4, 2016, p. 821. 4.PICU, O.E., BODRUG, V., Curierul Medical, 3, no. 315, 2010, p. 54. 5.PRABHAKAR, A.R., SHUBHA, A.B., MAHANTESH, T., Malays. Dent. J., 29, no.1, 2008, p. 6.

6.KAUFMAN, E., LAMSTER, I.B., Crit. Rev. Oral. Biol. Med., 13, no.2, 2002, p.197.

7.BATAiOSU, M,. OlTEANU, M., MAGLAVICEANU, C., Curs de Pedodonje, vol. 1, Ed. Universitaria, Craiova, 2019.

8.TANG, R.S., HUANG, M.C., HUANG, S.T., The Kaohsiung J. Med. Sci., 29, no. 6, 2013, p. 330.

9.SAVIN, C., PETCU, A., GAVRILA, L., MARTU-STEFANACHE, M.A., BALAN, A., International J ournal of Medical Dentistry, 20, no. 3, 2016, p. 171.

10.SOLOMON, S.M., STOLERIU, S., FORNA-AGOP, D., TIMPU, D., MARTU-STEFANACHE, M.A., URSARESCU, I.G., MARTU, S., Mat. Plast., 53, no. 2, 2016, p. 304.

11.LUCHIAN, I., VATA, I., MARTU, I. et al., Rom. J . Oral Rehab., 8, no.1, 2016, p. 80.
12.SOLOMON, S.M., TIMPU, D., FORNA-AGOP, D., MARTU-STEFANACHE, M.A., MARTU, S., STOLERIU, S. Mat. Plast., 53, no. 3, 2016, p. 546. 13.IGNAT, A., BURLEA, M., LUPU, V.V. et al., Rom. J. Oral Rehab., 9, no. 3, 2017, p. 40.

14.CIOCAN-PENDEFUNDA, A.A., MARTU, M.A., ANTOHE, M.E., et al., Rom. J. Oral Rehab. 10, no. 4, 2018, p. 91.

15.MARTU, A., REZUS, E., SUFARU, I. et al. Rom. J. Oral Rehab., 10, no. 3, 2017, p. 188.

16.MARTU, S., SOLOMON, S., POTARNICHIE, O., PASARIN, L., MARTU, A., NICOLAICIUC, O., URSARESCU, I., Int. J. Med. Dent., 3, no. 3, 2013, p. 212.

17.WRIGHT, J .T., MEYER, B.D., Anomalies of the Developing Dentition in Pediatric Dentistry, Part 1: Fundamentals of Pediatric Dentistry, in Arthur J. Nowak, John R. Christensen, Tad R. Mabry, Janice A. Townsend, Martha H. Wells, Pediatric Dentistry. Infancy through Adolescence (Sixth Edition), 2019, pp. 50-65.e3. https://doi.org/10.1016/ C2016-0-02300-8.

18.SURLIN, P., RAUTEN, A.M., PIRICI, D., Rom. J. Morph. Embryol., 53, no. 1, 2012, p.161.

19.SURLIN, P., RAUTEN, A.M., MATEESCU, G.O., Rom. J. Morph. Embryol., 50, no. 2, 2009, p. 181.

20.DAMLE, S.G., VIDYA, I., YADAV, R., BHATTAL, H., LOOMBA, A., Dentistry, 2, no. 3, 2012, p. 1.

21.SOARES, M.S.M., BATISTA-FILHO, M.M.V., PIMENTEL, M.J ., PASSOS, I.A., KUSTNER, E.C. Med. Oral Pathol. Oral. Chir. Bucal., 14, no. 9, 2009, p. 510.

22.CHIRIAC, A., BRZEZINSKI, P., STOLNICU, S., PODOLEANU, C., MOLDOVAN, C., MOLNAR, C., TARANU, T., J. Dermat. Treat., 27, no. 2, 2016, p.110.

23.BOGDAN, M., SILOSI, I., et al., Int. J. Clin. Exp. Med., 8, no. 5, 2015, p. 8051.

24.GARAN, A., AKYÜZ, S., OZTÜRK, L.K., YARAT, A., J. Clin. Pediatr. Dent., 36, no. 3, 2012, p. 285.

25.OLTEANU, M., et al., Rom. J. Morph. Embryol., 52, no. 4, 2011, p. 311.

26.PANICH, M., POOLTHONG, S., J. Am. Dent. Assoc., 140, 2009, p. 455.

27.ANDERSON, P., HECTOR, M.P., RAMPERSAD, M.A., Int. J. Paediatr. Dent., 11, 2001, p. 266.

Manuscript received:12.11.2019 